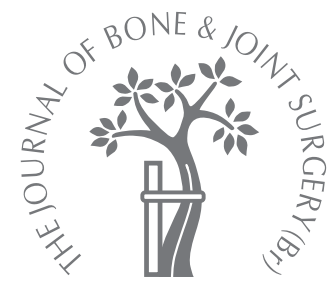

- ASPECTS OF CURRENT MANAGEMENT Mitigating surgical risk in patients undergoing hip arthroplasty for fractures of the proximal femur

A. J. Timperley, S. L. Whitehouse

From The Princess Elizabeth Orthopaedic Centre, Exeter, England

A. J. Timperley, MBChB FRCS(Ed), DPhil(Oxon), Consultant Orthopaedic Surgeon

Royal Devon and Exeter Hospital, Barrack Road, Exeter EX2 5DW, UK.

S. L. Whitehouse, BSc(Hons), $\mathrm{PhD}$, Biostatistician/Research Fellow

Institute of Health and

Biomedical Innovation Queensland University of Technology, Brisbane, Queensland 4032, Australia.

Correspondence should be sent to $\mathrm{Mr}$ A. J. Timperley; email: jtimperley@mac.com

(c)2009 British Editorial Society of Bone and Joint Surgery doi:10.1302/0301-620X.91B7. $22617 \$ 2.00$

$J$ Bone Joint Surg $[\mathrm{Br}]$ 2009;91-B:851-4.

\begin{abstract}
Recently the National Patient Safety Agency in the United Kingdom published a report entitled "Mitigating surgical risk in patients undergoing hip arthroplasty for fractures of the proximal femur". A total of $\mathbf{2 6}$ deaths had been reported to them when cement was used at hemiarthroplasty between October 2003 and October 2008. This paper considers the evidence for using cement fixation of a hemiarthroplasty in the treatment of hip fractures.
\end{abstract}

There has been a considerable increase in the incidence of fractures of the hip in patients in the western world, and the projected number of cases is estimated to double by $2050 .^{1}$ There is scope for improving both the quality and cost-effectiveness of the care of fragility fractures, and this has led to a number of publications and initiatives. In September 2007 a revised edition of the Blue Book, sponsored by the British Orthopaedic Association and the British Geriatrics Society, sought to summarise current best practice in the care and secondary prevention of these fractures. ${ }^{1}$ The National Hip Fracture Database ${ }^{2}$ supported by the National Clinical Audit Support Programme is a joint initiative between the British Orthopaedic Association and the British Geriatrics Society. Its aim is to focus attention on fractures of the hip with the ultimate aim of sustaining improvements in clinical standards and costeffectiveness. In March 2009 the National Patient Safety Agency published a Rapid Response Report entitled 'Mitigating surgical risk in patients undergoing hip arthroplasty for fractures of the proximal femur'. ${ }^{3}$ They cited 26 deaths of patients reported to them when cement had been used at hemiarthroplasty between October 2003 and October 2008. The Agency requires precautionary action to be taken by Clinical Directors throughout the National Health Service and the independent sector regarding patient assessment, anaesthetic technique and surgical technique, but does not make recommendations on the best form of fixation to use at hemiarthroplasty.

There is often confusion over the risks involved in using bone cement for fixation of the femoral component in the emergency situation for fractures compared to its use in elective hip arthroplasty. It is well recognised that the mortality rate in the former situation is much greater, and the most important risk factors are patient related. Prompted by the concerns that the latest National Patient Safety Agency report may raise, it is worth examining the evidence currently available concerning the fixation of an implant at hemiarthroplasty.

\section{Mortality rates}

Mortality rate after total hip replacement. The overall death rate within 30 to 90 days after total hip replacement (THR) ranges from $0 \%$ to $0.45 \% .^{4-9}$ There has been a significant decline in this rate over the last 15 years. Parry et $\mathrm{al}^{9}$ recently reported a reduction in 90-day mortality from $0.98 \%$ to $0 \%$, and in a total cohort of 30715 patients the rate was $0.15 \%$ for cases having surgery in the 1990 s compared with $0.94 \%$ in the 1970 s and $0.27 \%$ in the 1980s ( $\mathrm{p}<0.0002) .^{6}$ A single-surgeon series of 2736 hips reported a death rate of $0.18 \%$ if patients with severe pre-existing disease were excluded. ${ }^{7}$ Sharrock et al $^{6}$ studied the effect of changes in anaesthetic technique on the death rate, and mortality whilst in hospital was reduced to $0.18 \%$ with improved techniques. These rates are lower than the number of expected deaths in the normal population. Another study from the United States has confirmed that patients who have undergone THR survive longer than do a matched control Medicare population. ${ }^{10}$

At one year following THR the National Joint Registry ${ }^{11}$ reports a mortality rate of less than half that of the general population of England and Wales (1.9\%; 95\% confidence interval (CI) 1.8 to 2.0), using age- and gender-adjusted standardised mortality ratios. 
Indeed, this ratio is slightly less for cemented $(0.46 ; 95 \% \mathrm{CI}$ 0.42 to 0.50$)$ than for cementless $(0.49 ; 95 \%$ CI 0.42 to $0.57)$ joint replacements. The use of cement did not significantly influence the model when analysed using multivariate analysis, and the hazard ratios were similar $(0.9 ; 95 \%$ CI 0.8 to 1.1 ) when cement was not used.

Mortality rate for hip arthroplasty after proximal femoral fractures. The 30-day mortality in a cohort of 7774 hip arthroplasties was $2.4 \%$ (i.e. a tenfold higher rate) compared to THRs. ${ }^{12}$ The in-hospital mortality rates of 200000 THRs, 100000 partial hip replacements and 36000 revision hip replacements performed in the United States in 2003 were $0.33 \%, 3.04 \%$ and $0.84 \%$, respectively. ${ }^{13}$ The Swedish hemiarthroplasty register of approximately 12000 joints confirms the finding of a significantly increased risk in patients who have had a fracture. ${ }^{14}$ The 90-day mortality following hemiarthroplasty was over ten times greater $(12 \%)$ than with THR but the authors point out that the two patient groups are entirely different. Patients having a hemiarthroplasty following fracture are older, generally more ill, and are in need of an emergency operation with little time to stabilise their health state prior to surgery. The mortality rate was significantly higher if surgery was delayed for more than 48 hours.

Many studies have been unable to identify an increased risk of death with the use of cement, ${ }^{4,15-20}$ and one has in fact shown a reduction ${ }^{21}$ in the 30 -day mortality when cement is used.

In a study of 25000 hemiarthroplasties from the Australian Orthopaedic Association National Joint Replacement Registry an increased mortality rate was found on the first day after operation when cement was used $(p=0.0005) .{ }^{22}$ However, by one week this trend had reversed $(\mathrm{p}=0.02)$, and this persisted at one month $(\mathrm{p}=0.028)$ and one year $(\mathrm{p}<0.0001)$. Cemented hemiarthoplasties were the safer option for treatment at all time points after the day of surgery. Intra-operative deaths. One cause of sudden intra-operative death during arthroplasty is venous embolisation of marrow contents, which may occur during the reaming of any long bone. ${ }^{23} \mathrm{~A}$ fatal fat embolism has also been reported immediately following removal of the femoral head, prior to further preparation of the acetabulum or of the femoral shaft. ${ }^{24}$ This was presumably a consequence of the rise in intramedullary pressure during the processes of dislocation and resection of the femoral neck. At the time of arthroplasty it can occur when cement is used, ${ }^{7}$ but has also been observed with cementless implants. ${ }^{25,26} \mathrm{~A}$ randomised prospective study comparing cemented with uncemented femoral components in THR reported no difference in the prevalence of fat or bone marrow embolism. ${ }^{27}$

In a series of studies carried out in the Department of Chemistry of the University of Exeter and at the Princess Elizabeth Orthopaedic Hospital, ${ }^{28-30}$ the changes in blood pressure noted when cement was used were thought to be a consequence of fat embolism. Recommendations were made in Exeter ${ }^{23}$ and elsewhere ${ }^{31}$ for the prevention of these cardiovascular aberrations. Sierra et $\mathrm{al}^{4}$ reported a prevalence of sudden death of $0.01 \%$ during cemented THR in a series of 9082 total hips over a 17-year period, with one intra-operative death. Using current contemporary techniques of cementing and a specialised anaesthetic protocol, the author suggested that the incidence of sudden death during cemented THR should be 'near zero'.

Complications and re-operation after hemiarthroplasty. Many studies have noted an increase in the rate of periprosthetic fracture when cementless components are used in the treatment of these fragility fractures. ${ }^{21,32}$ The risk of intraoperative fracture in 1118 hemiarthroplasties was significantly increased $(\mathrm{p}<0.001)$ in uncemented compared to cemented implants. ${ }^{16}$ Foster et $\mathrm{al}^{21}$ advocated the use of cemented components and noted that, with modern cementing techniques, frail elderly patients are able to tolerate bone cement, which serves to reinforce an osteoporotic proximal femur and protect it from further fracture.

A randomised prospective study comparing cemented and uncemented components showed no increase in morbidity when cement was used, ${ }^{17}$ and this was confirmed in a review of the Cochrane database. ${ }^{15}$

There has been a review of the literature including the Cochrane Bone, Joint and Muscle Trauma Group Specialised Register (December 2005), the Cochrane Central Register of Controlled Trials (The Cochrane Library Issue 4, 2005), MEDLINE, EMBASE, the United Kingdom National Research Register, several orthopaedic journals, conference proceedings and reference lists of articles, for randomised prospective studies comparing different types of arthroplasty in the treatment of hip fractures. ${ }^{19}$ There was found to be no difference in the prevalence of surgical complications between cemented and uncemented arthroplasties.

The national arthroplasty registers that have studied the outcome of hemiarthroplasty observed an increase in the rate of re-operation with the use of uncemented components. Such an additional procedure carries a further risk of death or morbidity for the patient. In the Swedish register of 12000 hemiarthroplasties, ${ }^{14}$ uncemented components increased the risk of re-operation by 1.8 times $(95 \%$ CI 1.4 to 2.5 ). In a separate analysis of the most modern design of uncemented components the increased risk remained at 1.8 times (95\% CI 1.1 to 2.8 ) that of cemented components when adjusted for age, gender and secondary intervention. In the Australian Register considering over 25 000 cases $^{22}$ there was an improved survival with a cemented component regardless of the type used.

\section{Clinical outcome after arthroplasty in patients following fracture}

Numerous papers, including a Cochrane review and a report of a randomised prospective trial, show improved mobility and/or functional activity ${ }^{15,18-20,33}$ when a cemented component is used compared to an uncemented component and the use of a cemented component is associated with less pain. ${ }^{15,17-19}$ 


\section{Clinical outcome after arthroplasty in elective patients}

The lower revision rates for cemented arthroplasty and the increased mortality at revision also reduce the balanced risk of death. The National Joint Registry report ${ }^{11}$ records rates of revision at three months of $0.2 \%$ for cemented and $0.5 \%$ for cementless THRs, with the difference increasing at one year to $0.3 \%$ for cemented and $1.0 \%$ for cementless THRs. This trend continues at three years with $0.9 \%$ for cemented and $1.9 \%$ for cementless components. Coupled with a significantly increased rate of mortality at revision, ${ }^{13,34}$ the balanced risk of mortality is significantly reduced if cemented components are used at the primary operation.

\section{Peri-operative mortality: risk factors}

The risk factors associated with increased peri-operative mortality following THR when undertaken either electively or following trauma are well recognised. They include increasing age, $, 12,13,35,36$ with a peri-operative mortality of $0.34 \%$ in 66 - to 69 -year-olds rising to $3.75 \%$ when the patient is over 85 years of age. ${ }^{37}$ The presence of comorbidities, including cardiovascular and respiratory disease, is well documented. ${ }^{7,8,12,13,38}$ It was recommended in national clinical guidelines published by the Scottish Intercollegiate Guidelines Network that cement should be used when undertaking hemiarthroplasty unless there are cardiorespiratory complications. ${ }^{39}$

Every attempt should be made to optimise the medical condition of the patient before operation. ${ }^{10} \mathrm{~A}$ study has shown that hospitals with higher volumes of surgery have superior rates of in-patient mortality and reduced lengths of hospital stay. ${ }^{40}$

Anaesthetic and surgical techniques to reduce risk in fracture patients. Sharrock et $\mathrm{al}^{6}$ studied the effect of changes in anaesthetic care and found that modified techniques reduced the risk of death after THR from $0.36 \%$ to $0.1 \%$. The patients most at risk are those with limited cardiac reserve or with hypovolaemia, as they are less able to compensate by vasoconstriction for any drop in blood pressure caused by reaming or by the cement. ${ }^{41}$ There should be vigilant intra-operative management of the patients by the anaesthetist.

In summary, reduction of risk relies on recognition of the patient who is at risk and constant monitoring throughout the operation; assessent of cardiac filling as there must be adequate fluid loading to increase the response to low cardiac output; use of vasoconstrictors/inotropes if hypotension does occur. ${ }^{42}$

Intraoperatively, every effort should be made to reduce the possibility of embolisation of fat and marrow contents, whether the arthroplasty is to be cemented ${ }^{38}$ or not. ${ }^{24,26,43}$ Pressurised lavage. Thorough lavage of the medullary cavity with a pressurised system is mandatory to reduce the embolic load. ${ }^{31,44,45}$ It has also been shown to improve fixation of the femoral component. ${ }^{46}$ Lavage should be carried out before instrumentation of the medullary cavity. ${ }^{47}$
Suction catheter. The safest way to introduce cement is in a retrograde fashion from a gun. A suction catheter must be placed distally above the plug to reduce pressure at the cement/marrow vessel interface during insertion of the cement. ${ }^{38}$ A reduction in intramedullary pressure has been reported to lead to a threefold reduction in the rate of intraoperative mortality. ${ }^{38}$ If the canal is adequately cleaned and if the patient is properly prepared and monitored during the procedure, pressurisation of the cement appears to confer no disadvantage as regards risk and improves fixation of the femoral component. ${ }^{4,11,14}$

\section{Conclusion}

The National Patient Safety Agency recorded 26 deaths after use of cement over a period when approximately 500000 patients would have had a cemented femoral component inserted, giving a prevalance of $0.000052 \%$. Although the recommendations made in the report are to be supported, there is clearly a need for a National Hip Fracture Database to provide more accurate and relevant data in order to plan better treatment for this vulnerable group of patients.

There is currently a large body of work supporting the use of cement for hip arthroplasty after fracture. Appropriate fixation of the femoral component with cement carries no additional risk of mortality and will lead to a reduced rate of peri-operative fracture, a reduction in the rates of re-operation and revision, less pain, a better functional outcome and an overall lower risk of death for patients compared to the use of uncemented components. The National Hip Fracture Database and the results from national joint registries will allow us to define the optimal treatment for these patients in the future.

The author or one or more of the authors have received or will receive benefits for personal or professional use from a commercial party related directly or indirectly to the subject of this article. In addition, benefits have been or will be directed to a research fund, foundation, educational institution, or other nonprofit organisation with which one or more of the authors are associated.

\section{References}

1. Marsh D. The care of patients with fragility fracture. London: British Orthopaedic Association, 2002

2. No authors listed. The national hip fracture database. http://nhfd.co.uk (date last accessed 28 May 2009).

3. Cleary K. Mitigating surgical risk in patients undergoing hip arthroplasty for fractures of the proximal femur. National Patient Safety Report NPSA/2009/RRR001.

4. Sierra RJ, Timperley JA, Gie GA. Contemporary cementing technique and mortality during and after Exeter total hip arthroplasty. J Arthroplasty 2009;24:325-32.

5. Nunley RM, Lachiewicz PF. Mortality after total hip and knee arthroplasty in a medium-volume university practice. J Arthroplasty 2003;18:278-85.

6. Sharrock NE, Cazan MG, Hargett MJ, Williams-Russo P, Wilson PD Jr. Changes in mortality after total hip and knee arthroplasty over a ten-year period. Anesth Analg 1995;80:242-8.

7. Dearborn JT, Harris WH. Postoperative mortality after total hip arthroplasty: an analysis of deaths after two thousand seven hundred and thirty-six procedures. J Bone Joint Surg [Am] 1998;80-A:1291-4.

8. Parvizi J, Johnson BG, Rowland C, Ereth MH, Lewallen DG. Thirty-day mortality after elective total hip arthroplasty. J Bone Joint Surg [Am]2001;83-A:1524-8.

9. Parry M, Wylde V, Blom AW. Ninety-day mortality after elective total hip replacement: 1549 patients using aspirin as a thromboprophylactic agent. J Bone Joint Surg [Br] 2008;90-B:306-7

10. Barrett J, Losina E, Baron J, et al. Survival following total hip replacement. J Bone Joint Surg [Am] 2005;87-A:1965-71. 
11. No authors listed. The National Joint Registry 5th Annual Report. Hemel Hemstead: National Joint Registry for England and Wales, 2009.

12. Parvizi J, Ereth MH, Lewallen DG. Thirty-day mortality following hip arthroplasty for acute fracture. J Bone Joint Surg [Am]2004;86-A:1983-8.

13. Zhan C, Kaczmarek R, Loyo-Berrios N, Sangl J, Bright R. Incidence and short-term outcomes of primary and revision hip replacement in the United States. J Bone Joint Surg [Am]2007;89-A:526-33.

14. No authors listed. Department of Orthopaedics SUH. Swedish Arthroplasty Register Annual Report 2007. http://www.jru.orthop.gu.se (date last accessed 1 March 2009).

15. Parker MJ, Gurusamy K. Arthroplasties (with and without bone cement) for proximal femoral fractures in adults. Cochrane Database Syst Rev 2006;3:CD001706.

16. Weinrauch PC, Moore WR, Shooter DR, et al. Early prosthetic complications after unipolar hemiarthroplasty. ANZ J Surg 2006;76:432-5.

17. Emery RJ, Broughton NS, Desai K, Bulstrode CJ, Thomas TL. Bipolar hemiarthroplasty for subcapital fracture of the femoral neck: a prospective randomised trial of cemented Thompson and uncemented Moore stems. J Bone Joint Surg [Br] 1991;73B:322-4.

18. Khan RJ, MacDowell A, Crossman P, et al. Cemented or uncemented hemiarthroplasty for displaced intracapsular femoral neck fractures. Int Orthop 2002;26:229-32.

19. Khan RJ, MacDowell A, Crossman P, Keene GS. Cemented or uncemented hemiarthroplasty for displaced intracapsular fractures of the hip: a systematic review. Injury 2002;33:13-17.

20. Lo WH, Chen WM, Huang CK, et al. Bateman bipolar hemiarthroplasty for displaced intracapsular femoral neck fractures: uncemented versus cemented. Clin Orthop 1994;302:75-82.

21. Foster AP, Thompson NW, Wong J, Charlwood AP. Periprosthetic femoral fractures: a comparison between cemented and uncemented hemiarthroplasties. Injury 2005;36:424-9.

22. Costain DJ, Whitehouse SL, Pratt NL, et al. A review of peri-operative mortality after hemiarthroplasty using the Australian Orthopedic Association National Joint Replacement Registry. Procs Canadian Orthopaedic Meeting 2009

23. Ling RSM. Complications of total hip replacement. First ed. Edinburgh: Churchill Livingstone, 1984:288.

24. Walker N, Bateson T, Reavley P, Prakash D. Fatal fat embolism following femoral head resection in total hip arthroplasty. Hip Int 2008;18:332-4.

25. Gelinas JJ, Cherry R, MacDonald SJ. Fat embolism syndrome after cementless total hip arthroplasty. J Arthroplasty 2000;15:809-13.

26. Arroyo JS, Garvin KL, McGuire MH. Fatal marrow embolization following a porouscoated bipolar hip endoprosthesis. J Arthroplasty 1994;9:449-52.

27. Kim YH, Oh SW, Kim JS. Prevalence of fat embolism following bilateral simultaneous and unilateral total hip arthroplasty performed with or without cement: a prospective, randomized clinical study. J Bone Joint Surg [Am]2002;84-A:1372-9.

28. Corkill J, Lloyd E, Hoyle P, et al. Toxicology of methylmethacrylate: the rate of disappearance of methylmethacrylate in human blood in vitro. Clin Chim Acta 1976;68:141-6.

29. Crout D, Corkill J, James M, Ling R. Methylmethacrylate metabolism in man: the hydrolysis of methylmethacrylate to methacrylate acid during total hip replacement. Clin Orthop 1979;141:90-5.
30. Crout D, Lloyd E, Singh J. Metabolism of methyl methacrylate: evidence for metabolism by the valine pathway of catabolism in rat and in man. Xenobiotica 1982;12:821-9.

31. Byrick R, Bell R, Kay J, Waddell J, Mullen J. High-volume, high-pressure pulsatile lavage during cemented arthroplasty. J Bone Joint Surg [Am] 1989;71-A:1331-6.

32. Weinrauch P, Myers N, Wilkinson M, et al. Comparison of early postoperative rehabilitation outcome following total knee arthroplasty using different surgical approaches and instrumentation. J Orthop Surg (Hong Kong) 2006;14:47-52.

33. Lausten GS, Vedel P. Cementing v not cementing the Monk endoprosthesis. Injury 1982;13:484-8.

34. Sharkey P, Shastri S, Teloken M, et al. Relationship between surgical volume and early outcomes of total hip arthroplasty: do results continue to get better? J Arthroplasty 2004;19:694-9.

35. Holt G, Smith R, Duncan K, Hutchison J, Gregori A. Epidemiology and outcome after hip fracture in the under 65s: evidence from the Scottish Hip Fracture Audit. Injury 2008;39:1175-81.

36. Holt G, Smith R, Duncan K, Hutchison J, Gregori A. Outcome after surgery for the treatment of hip fracture in the extremely elderly. J Bone Joint Surg [Am]2008;90-A:1899905

37. Whittle J, Steinberg EP, Anderson GF, Herbert R, Hochberg MC. Mortality after elective total hip arthroplasty in elderly Americans: age, gender, and indication for surgery predict survival. Clin Orthop 1993;295:119-26

38. Parvizi J, Holiday AD, Ereth MH, Lewallen DG. The Frank Stinchfield Award: sudden death during primary hip arthroplasty. Clin Orthop 1999;369:39-48.

39. Currie C, Hutchison J, eds. SIGN. Prevention and management of hip fractures in older people: a national clinical guideline. Edinburgh: Scottish Intercollegiate Guidelines Network, 2002:44.

40. Doro C, Dimick J, Wainess R, Upchurch G, Urquhart A. Hospital volume and inpatient mortality outcomes of total hip arthroplasty in the United States. J Arthroplasty 2006;21(Suppl 2):10-16.

41. Sinclair S, James S, Singer M. Intraoperative intravascular volume optimisation and length of hospital stay after repair of proximal femoral fracture: randomised controlled trial. BMJ 1997;315:909-12.

42. Dow A. We need a good anaesthetist for cemented THA. In: Breusch SJ, Malchau H, eds The well cemented total hip arthroplasty. Berlin: Springer Medizin Verlag, 2005:302-6.

43. Pitto RP, Koessler M, Draenert K. The John Charnley Award: prophylaxis of fat and bone marrow embolism in cemented total hip arthroplasty. Clin Orthop 1998;355:23-34.

44. Christie J, Robinson CM, Singer B, Ray DC. Medullary lavage reduces embolic phenomena and cardiopulmonary changes during cemented hemiarthroplasty. J Bone Joint Surg [Br] 1995;77-B:456-9.

45. Breusch S, Reitzel T, Schneider U, et al. Cemented hip prosthesis implantation: decreasing the rate of fat embolism with pulsed pressure lavage. Orthopade 2000;29:57886 (in German).

46. Malchau H, Herberts P, Soderman P, Oden A. Prognosis of total hip replacements: update and validation of results from the Swedish National National Hip Arthroplasty Registry 1979-1998. Procs 67th Annual Meeting American Academy of Orthopaedic Surgeons, 2000.

47. Clarius M, Heisel C, Breusch SJ. Pulmonary embolism in cemented total hip arthroplasty. In: Breusch SJ, Malchau H, eds. The well cemented total hip arthroplasty. Berlin Springer Medizin Verlag, 2005:320-31. 